\title{
SEMEN ANALYSIS; CORNER STONE IN EVALUATING INFERTILITY
}

\author{
Aysha Khan, Zunera Sajjad, Shagufta Yousaf, Abeera Ahmed, Fatima Sana, Fawad Sana
}

Combined Military Hospital Kharian/National University of Medical Sciences (NUMS) Pakistan

\begin{abstract}
Objective: To study the patterns and distribution of various abnormal semen parameters in infertile males. Study Design: Cross sectional study.

Place and Duration of Study: Department of Pathology, Combined Military Hospital, Karachi, from Nov 2019 to Oct 2020.

Methodology: The study included 364 patients who presented with primary and secondary infertility. Consecutive convenient sampling was done. Semen analysis was performed using World Health Organization (WHO) latest guidelines. Samples were categorized as normospermia, azoospermia, oligospermia, asthenozoospermia and necrospermia.

Results: The study comprised of 364 samples of infertile males. Normal sperm count was observed in 317 (87\%) males, azoospermia in 28 (7.6\%) and oligospermia in 19 (5.2\%) males. Low ejaculated volume and higher non-motile sperms were noted in oligospermia samples in comparison with normospermia samples. Asthenozoospermia was observed in 102 (28\%) and oligoasthenospermia was noted in $15(4.1 \%)$ samples.

Conclusion: Good quality semen analysis is a corner stone to diagnose the cause of male infertility.

Sperm concentration and motility are the important markers of normal male reproductive system and are related to each other.
\end{abstract}

Keywords: Asthenozoospermia, Azoospermia, Necrospermia, Oligospermia, Sperms.

How to Cite This Article: Khan A, Sajjad Z, Yousaf S, Ahmed A, Sana F, Sana F. Semen Analysis; Corner Stone in Evaluating Infertility. Pak Armed Forces Med J 2021; 71(6): 2224-2227. Doi: https://doi.org/10.51253/pafmj.v71i6.6150

This is an Open Access article distributed under the terms of the Creative Commons Attribution License (https://creativecommons.org/licenses/by-nc/4.0/), which permits unrestricted use, distribution, and reproduction in any medium, provided the original work is properly cited.

\section{INTRODUCTION}

Semen analysis is a basic test carried out in an infertile couple who are living together for at least one year with healthy sexual relationship, but are unable to reproduce a child without using any contraceptive measures. ${ }^{1}$ Approximately $10-15 \%$ of couples suffer from infertility throughout the world. Male factor is responsible for $45 \%$ of such cases. ${ }^{2}$ However, in our society females have to endure the infertility trauma and undergo wide range of tests, including invasive procedures causing physical and emotional trauma.

Semen analysis remains the basic and fundamental test in evaluation of infertility. Not only it provides an insight into fertility but also if used in broader sense, it can help in evaluation of male reproductive system and may give a clue about any serious underlying disorder. Semen analysis may also be requested for evaluation of hypogonadism, follow up after vasectomy, prior to donation for artificial insemination and storage of semen before radiotherapy etc. ${ }^{3}$

Semen analysis also reveals important information about sperm production, its motility and viability, patency of male genital tract, secretion of accessory

Correspondence: Dr Aysha Khan, Department of Haematology, Combined Military Hospital, Malir Pakistan

Received: 16 Feb 2021; revision received: 02 Oct 2021; accepted: 25 Oct 2021 organs as well as ejaculation and emission.

Semen consists of spermatozoa suspended in fluid like material necessary for its nourishment. Only sperms and $5 \%$ of the total volume of semen are produced in testes. About $40-80 \%$ of the secretions come from seminal vesicles, which contain fructose necessary for nourishment of the sperms. Out of $13-33 \%$ of the bulk comes from prostate that contains a number of enzymes including citrates, calcium, zinc etc. Approximately, $2-5 \%$ of the volume is also contributed by bulbourethral and urethral glands that contain mucoproteins and immunoglobulin A. The ability to penetrate the egg is also acquired in epididymis. White blood cells (WBCs) may also be present in semen. If in excess, they are referred to as leukocytospermia or pyospermia that may indicate infection of the genital tract. WBCs are also known to adversely affect motility of the sperms. Thus, the disease in any of these parts may have a significant effect on quantity and quality of the semen. ${ }^{4}$

The aim of this study was to assess different patterns and distribution of abnormal semen parameters in infertile males.

\section{METHODOLOGY}

This cross sectional study was conducted at the Department of Pathology, Combined Military Hospital 
(CMH) Malir, from November 2019 to October 2020. The study included 364 male patients that presented to the male outpatient department (OPD).

Inclusion Criteria: Male patients between ages of 20-55 years, with the history of primary or secondary infertility were included in the study.

Exclusion Criteria: Individuals who did not give consent or did not come in the specified time i.e. within 3-7 days of coitus, were also excluded.

Sample was collected by non-probability consecutive sampling technique with the help of World Health Organization (WHO) sample size calculator. While keeping Confidence interval at $95 \%$, margin of error of $5 \%$ and prevalence at $15 \%$, sample size was calculated as $196 . .^{5}$ The study was conducted after approval by the Ethical Committee of CMH Malir [31/2020/trg]. The patients selected for the study were referred by the gynecologists for workup of primary as well as secondary infertility at the Department of Pathology, $\mathrm{CMH}$ Malir. All the subjects fulfilling the inclusion criteria were explained about the study. Informed consent was taken and patients' particulars were endorsed on a performa.

Semen sample was collected in wide mouth sterile bottle after 3-5 days of abstinence from coitus. Sample collection was preferred in laboratory; however, some of the samples were also produced at home and quickly delivered to laboratory in less than an hour time. A questionnaire was filled at time of receiving of the sample. Information was gathered regarding age, duration of marriage, first or second marriage, and whether the couple is living together. In case of secondary infertility, age of last childbirth, use of drugs/medicine and any other systemic illness/surgery taken place.

WHO 2010 parameters 3 were followed while examining these samples. Macroscopically, appearance liquefaction, $\mathrm{pH}$ and volume were noted. Normal colour was taken as grey or dirty white, liquefaction time $20 \mathrm{~min}, \mathrm{pH} 7.2-8$ and volume more than $1.5 \mathrm{ml}$ were taken as normal. Microscopically, sperm concentration of $>15.0 \times 10^{6}$ spermatozoa/ ml, motility $>40 \%$ (both progressive and non-progressive motility), $>4 \%$ normal heads and vitality of $>58 \%$ at $1^{\text {st }}$ hour was taken as normal.

Following terms were used using WHO criteria 3; Azoospermia: Absence of sperms in ejaculate, oligospermia: sperm count below $15 \times 10^{6}$, asthenozoospermia: reduced sperm motility and necrospermia: dead sperms. Sample was placed at $37^{\circ} \mathrm{C}$ and was analyzed within one hour. Observation was made for abovementioned parameters both macro and microscopically. All the relevant data was analyzed through Statistical Package for the social sciences (SPSS) version 23. Numerical variables were presented by mean \pm SD. Categorical variables were presented by frequency and percentage.

\section{RESULTS}

A total of 364 samples were included in this study. Mean age of patients was 30.8 years \pm 5.0 years. Primary infertility was present in 295 (81\%) while secondary infertility was present in $69(19 \%)$ patients. Out of 364 samples $356(97.8 \%)$ had normal semen volume, $06(1.6 \%)$ showed hypospermia while $2(0.5 \%)$ showed hyperspermia (Table-I). Sperm concentration was normal in 317 (87\%) samples and oligospermia in 19 (5.2\%) samples (Table-II). No abnormality was found in $210(57.7 \%)$ samples. Most common abnormality was asthenozoospermia observed in $102(28 \%)$ of patients, followed by azoospermia $28(7.7 \%)$, necrospermia 5 (1.4\%), oligoasthenospermia $15(4.1 \%)$ and oligospermia 4 (1.1\%) samples (Table-III). No abnormality of liquefaction was found in any sample. Pus cells were present in 75 samples.

Table-I: Distribution of sperm volume.

\begin{tabular}{l|c}
\hline Sperm volume & Frequency (\%) \\
\hline Normal volume $(1.5-4.5 \mathrm{ml})$ & $356(97.8)$ \\
\hline Hypospermia $(<1.5 \mathrm{ml})$ & $6(1.6)$ \\
\hline Hyperspermia $(>4.6 \mathrm{ml})$ & $2(0.5)$ \\
\hline
\end{tabular}

\begin{tabular}{l|c}
\hline \multicolumn{2}{l}{ Table-II: Frequency of sperm concentration. } \\
\hline Sperm Concentration & Frequency (\%) \\
\hline Normospermia & $317(87.2)$ \\
\hline Oligospermia & $19(5.2)$ \\
\hline Azoospermia & $28(7.6)$ \\
\hline
\end{tabular}

Table-III: Distribution of semen analysis parameters.

\begin{tabular}{l|c}
\hline Semen Analysis Parameters & Frequency (\%) \\
\hline Essentially Within normal limits & $210(57.7)$ \\
\hline Asthenospermia & $102(28.2)$ \\
\hline Azospermia & $28(7.6)$ \\
\hline Necrospermia & $5(1.4)$ \\
\hline Oligoasthenospermia & $15(4.1)$ \\
\hline Oligospermia & $4(1.1)$ \\
\hline
\end{tabular}

\section{DISCUSSION}

Infertility is a taboo that targets only the female population in our society and has a considerable impact on their mental and psychological health although males equally contribute towards this problem. Advanced knowledge of reproductive techniques provides wide range of treatment options, giving light of hope 
for infertile couples. Semen analysis is the fastest, easiest, cost-effective and reliable test giving a large amount of information without any invasive test.

Primary and secondary infertility both are common in our part of the world, contrary to belief that if men have fathered a child once, they remain fertile throughout their lives. In the study by Aulia et al ${ }^{6}$ and Haifa and Turki, ${ }^{7}$ primary infertility was reported to be $88.7 \%$ and $80.5 \%$ while secondary infertility was $11.3 \%$ and $19.5 \%$ respectively.

The mean sperm count in our study was $83.5 \pm 6.5$ million which was comparable to the study in UK, in which semen analysis was performed on a population of 1801 suspected infertile men, in which the mean sperm density was $84.3 \pm 7.89$, contradicting the fact that sperm count is declining over the years as predicted by Carlsen et al ${ }^{9}$, mean sperm count as reviewed by Virtanen et al is $41-55 \times 10^{6} / \mathrm{ml}$ showing a downward trend. ${ }^{10}$

Considerable attention was paid to the study of Carlsen et al that over the past 50-60 years, globally sperm density has decreased by about $50 \% .{ }^{9}$ Similar study was carried out in Wuhan city of China that concluded declining sperm count in their country. ${ }^{11} \mathrm{In}$ another study conducted in India by Mishra et al to confirm the hypothesis of declining sperm count in men also shows decline in sperm concentration. ${ }^{12}$ However, Elia et al performed a comparative study of seminal parameters between samples collected in 1992 and 2010 stating no change in sperm count over these years. ${ }^{13}$ Dietary patterns might lead to decline in sperm count as concluded by study of Anna et al in Poland.14 In Pakistan situation is not as devastating as in other parts of world due to low frequency of urogenital infections, testicular cancers and limited environmental exposure/eatables containing estrogen like activity hindering spermatogenesis. Our study gave some insight over the situation in Pakistan. Although study was conducted in one year and longer duration studies are required to confirm the situation in Pakistan.

Our study revealed azoospermia in 28 (7.6\%) of males, which was comparable to study by Jairajpuri et al from Delhi in which azoospermia was $9 \% 15$ and Ramya et al reported 7.5\%.16 Much lower percentage was reported by Anuja et al from Devanahalli as $2 \% .{ }^{17}$ One of the Pakistani study by Fouzia et al shows Azoospermia to be $14.89 \% .{ }^{5}$ Much higher percentage of azoospermia is also recorded in Jakarta as $24.4 \% .^{6}$ It may be due to referral center where only confirmed infertility cases visit.
Oligospermia (sperm count less than $15 \times 10^{6} \mathrm{ml}$ ) was reported to be $5.2 \%$ in our study. Abnormalities in accessory sex glands fluid synthesis may lead to low ejaculated volume. Seminal vesicle produces about $70 \%$ of seminal plasma. Physical obstruction and retrograde ejaculation may also contribute to low ejaculated volume. Anuja et al17 reported $6 \%$ oligospermia which was comparable to our study, while Fouzia et al reported $5(11.11 \%)$ same as $13.3 \%$ by Chituri et al. ${ }^{16}$ A very high percentage of oligospermia as $39.7 \%$ is reported by Aulia et al from Jakarta may be for the same reason as they reported higher percentage of azoospermia. ${ }^{6}$

Mean ejaculated volume in normopspermia was $3.25 \pm 1.35$ vs $2.05 \pm 2$ in oligospermia and $2.43 \pm 1.19$ in azoospermia sample respectively. Low ejaculated volume is defined as $<1.5 \% \mathrm{ml}$. Majority of our patients had normal semen volume $97.84 \%$, while $1.6 \%$ showed hypospermia $(<1.5 \mathrm{ml})$, and hyperspermia in $0.5 \%$. These results were comparable to a study conducted in Delhi, ${ }^{10}$ and Dewanhalli, ${ }^{17}$ which revealed $91 \%$ and $92 \%$ normal semen volume, while $4.9 \%$ and $7 \%$ having hypospermia (less than $1.5 \mathrm{ml}$ ) respectively. Similar results are also shown by Fauzia et al..$^{5}$ The adequacy of semen volume in our study could be the result of sexual abstinence of 3-4 days. Our study proposes that 3-4 days of sexual abstinence is required for proper collection and accurate analysis of semen. The volume plays little or probably no role in etiology of male infertility.

Another morbidity factor is male genital tract infections. It is known to affect not only the quality but also the environment that provides nourishment to sperms.

Epididymal proteins and other substances produce some conformational changes in sperms. They greatly influence the motility of sperms, which enhances while passing through epididymis. Therefore, sperm motility is an essential factor required for sperm to travel a long distance to fertilize the oocyte. Sperm motility is the pivotal factor of epididymal functioning. Asthenozoospermia is the most common abnormality found in our study. The mean percentage of normal motile sperms was $57 \% \pm 9.76$ in normospermia samples as compared to oligospermia in which motile sperms were $28 \% \pm 10 \%$. In our study, asthenozoospermia was observed in $28 \%$ of samples and comparable results were obtained from a studies conducted by Butt et $a l^{5}(25.81 \%)$ and Aulia et al $(22.1 \%)$, while much lower percentage is reported by Jarajpuri et al ${ }^{15}$ (5.9\%), Ramya et $a^{16}(4.4 \%)$ and by Anuja et al ${ }^{17}(3 \%)$. 
Another morbidity factor is male genital tract infections. It is known to affect not only the quality but also the environment which provides nourishment to sperms. ${ }^{18,19}$ In our study, we couldn't link any bacterial infection having direct relationship with sperm count or sperm motility. However, we are still working in collaboration with microbiologist with large sample size and results will be available soon.

\section{CONCLUSION}

Good quality semen analysis is a corner stone to diagnose the cause of male infertility. Concentration and motility of sperms are the main parameters that indicate normal male reproductive functioning.

Conflict of Interest: None.

\section{Authors' Contribution:}

AK: Concept, design, ZS: Data analysis, SY: Data interpretation, AA: Intellectual, FS: Data analysis, FS: Data analysis.

\section{REFERENCES}

1. Practice Committee of the American Society for Reproductive Medicine. Definitions of infertility and recurrent pregnancy loss:a committee opinion. Fertil Steril 2013; 99(1): 63.

2. Bennett LR, Wiweko B, Bell L, Shafira N, Pangestu M, Putra IB, et al. Reproductive knowledge and patient education needs among Indonesian women attending three fertility clinics: Patient education and counselling. Reprod Health 2014; 98(3): 364-369.

3. WHO. WHO Laboratory Manual for the Examination and Processing of Human Semen. 5th ed. Geneva: WHO; 2010, [Internet] Avalilable at: https://apps.who.int/iris/handle/ $10665 / 44261$.

4. Jequier AM. Semen analysis: a new manual and its application to the understanding of semen and its pathology. Asian J Androl 2010; 12(1): 11-13.

5. Butt F, Akram N. Semen analysis parameters: Experiences and insight into male infertility at a tertiary care hospital in Punjab. J Pak Med Assoc 2013; 63(5): 558-562.

6. Aulia SN, Lesttari SW, Pratama G, Harfzif AK, Smapraja K, Hestiantoro A, et al. The pattern of abnormalities on sperm analysis: A study of 1186 infertile male in Yasmin IVF clinic Jakarta. J Phys Conf Ser 2017; 884(1): 121-138.

7. Haifa A, Turki A. Prevalence of primary and secondary infertility from tertiary center in eastern Saudi Arabia. Middle East Fertil Soc J 2015; 20(4): 237-240.

8. Mortimer D, Templeton AA, Lenton EA, Coleman RA. Semen Analysis Parameters and Their Interrelationships in Suspected Infertile Men. Arch Androl 1982; 8(1): 165-171.

9. Carlsen E, Giwercman A, Keiding N, Skakkebaek NE. Evidence for decreasing quality of semen during past 50 years. BMJ 1992; 305(6854): 609-613.

10. Virtanen H, Jørgensen N, Toppari J. Semen quality in the 21st century. Nat Rev Urol 2017; 14(2): 120-130.

11. Yuan HF, Shangguan HF, Zheng $Y$, Meng TQ, Xiong CL, Guan HT. Decline in semen concentration of healthy Chinese adults: evidence from 9357 participants from 2010 to 2015. Asian J Androl 2018; 20(4): 379.

12. Mishra $P$, Negi MPS, Srivastava M. Decline in seminal quality in Indian men over last 37 years. Reprod Biol Endocrinol 2018; 16(1): 103.

13. Elia J, Imbrogno N, Delfino M, Rossi T, Mazzilli R, Nofroni I, et al. Comparative study of seminal parameters between samples collected in 1992 and samples collected in2010. Arch Ital Urol Androl 2012; 84(1): 26-31.

14. Danielewicz A, Przybyłowicz KE, Przybyłowicz M. Dietary Patterns and Poor Semen Quality Risk in Men: A Cross-Sectional Study: Nutrients 2018; 10(9): 1162.

15. Jairajpuri ZS, Rana S, Ali MA, Pujani M, Jetley S. Patterns of semen analysis: experiences of a laboratory catering to semi urban population of Delhi. Bangladesh Med J 2017; 16(2): 319344.

16. Ramya C, Renuka IV, Premalatha P , Madhavi K. Patterns of semen analysis in male partners of infertile couples at a tertiary care hospital. Indian J Pathol Oncol 2017; 4(4): 536-539.

17. Dasgupta A, Sandeepa S, Uma K, Subhashini R. Study on the patterns of semen analysis in infertile males at a tertiary setup in Devanahalli. Int J Clin Diagn Pathol 2020; 3(3): 39-42.

18. Farsimadan M, Motamedifar M. Bacterial infection of the male reproductive system causing infertility. J Reprod Immunol 2020; 142(1): 103183.

19. Stojanov M, Baud D, Greub G Vulliemoz, N. Male infertility: The intracellular bacterial hypothesis. New Microbes New Infect 2018; 26(1): 37-41. 